\title{
Three-Dimensional Fully Symmetric Inductors, Transformer, and Balun in CMOS Technology
}

\author{
Wei-Zen Chen, Member, IEEE, Wen-Hui Chen, and Kuo-Ching Hsu
}

\begin{abstract}
This paper presents novel three-dimensional (3-D) symmetric passive components, including inductors, transformers, and balun. Layout areas of these components are drastically reduced by $32 \%$ to $70 \%$, while the symmetry of the input and the output ports is still maintained. The inductance mismatch in the 3-D transformer is less than $0.1 \%$, and the coupling coefficient can be up to 0.77. The 3-D balun manifests less than 0.6-dB gain mismatch for $10-\mathrm{GHz}$ range, and the phase error is less than $7^{\circ}$ from 1- to $10-\mathrm{GHz}$ frequency range according to measurement results. Furthermore, the self-resonant frequency $\left(f_{\mathrm{SR}}\right)$ of the proposed architecture is improved by $32 \%$ to $61 \%$ in contrast to their planar counterparts. On the other hand, the quality factor is degraded by less than 2 for the sake of using lower metal layers. The distributed capacitance model is utilized to validate their superiorities in $f_{\mathrm{SR}}$. All the devices are fabricated in a generic 0.18- $\mu \mathrm{m}$ CMOS process.
\end{abstract}

Index Terms-Balun, coupling coefficient, self-resonant frequency, transformer, 3-dimensional inductor.

\section{INTRODUCTION}

W ITH the blooming progress in VLSI technologies, system/radio on a chip (SOC/ROC) has become a prominent trend for circuit design in the nanometer-scaled CMOS era. Monolithic passive components, including inductors, transformers, and baluns, have been widely used in RF ICs design, such as low noise amplifier [1], mixer [2], and oscillators [3], etc. These components play a key role in the circuit integration, and in general have significant impacts on the overall system performance. In these applications, major issues of the passive components are quality factor, self-resonant frequency, chip area, and coupling coefficient (for transformer and balun). On the other hand, for broad band amplifier design under a low supply voltage, shunt/series peaking techniques utilizing inductor or transformer are often adopted for bandwidth enhancement. In these cases, the self-resonant frequency $\left(f_{\mathrm{SR}}\right)$ of the inductor is more demanding than its quality factor. As the operating frequency exceeds $f_{\mathrm{SR}}$, the peaking inductor would become a capacitive load and dominate the achievable operating speed of the circuit. Furthermore, the chip area of

Manuscript received March 17, 2007; revised September 15, 2006 and February 10,2007. This work was supported in part by the National Science Council under Project NSC-95-2220-E009-033, by Mediatek Inc., and by ITRI/STC. This paper was recommended by Associate Editor K. Chakrabarty.

W.-Z. Chen and K.-C. Hsu are with the Department of Electronics Engineering, National Chiao-Tung University, Hsin-Chu 300, Taiwan, R.O.C. (e-mail:wzchen@mail.nctu.edu.tw).

W.-H. Chen was with National Central University, Chung-Li 32001, Taiwan, R.O.C. She is now with STC/ITRI, Hsin-Chu 300, Taiwan, R.O.C.

Digital Object Identifier 10.1109/TCSI.2007.899628

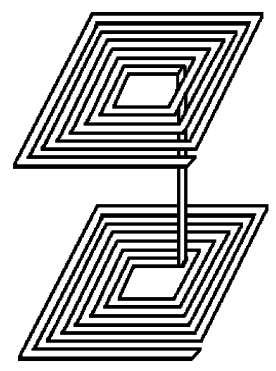

(a)

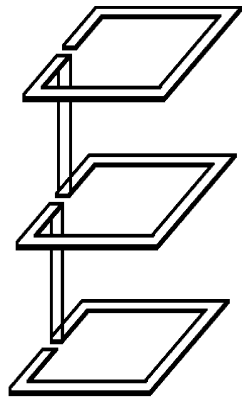

(b)
Fig. 1. (a) Stacked inductors. (b) Miniature 3-D inductors.

the passive components is also a critical concern, especially in some applications where lots of passive components are required, such as a limiting amplifier design [4].

Recently, several passive component architectures with improved performance have been proposed, including stacked inductors [Fig. 1(a)], miniature 3-D inductors [5] [Fig. 1(b)] [6], symmetric planar inductors, transformers, and baluns [7], [8].

Also, other techniques to improve the quality factor and selfresonant frequency of the passive components have been addressed [9]-[13]. Conventionally, these passive components are laid out in a planar spiral shape, which occupies significant chip area, especially for balun and transformer design. Although [5] and [6] propose stacked architectures to reduce the chip area, but those miniaturized inductors are basically asymmetric, as are illustrated in Fig. 1.

This paper proposes novel 3-D miniaturized passive components while maintaining the symmetry of both the input and the output ports [21]. In the RF or broad band integrated circuits (ICs) designs, fully differential architectures are preferable for they have higher common mode noise immunity. Our proposed passive components can be utilized to replace two asymmetric counterparts in these designs, so as to save chip area and cost. Also, they manifest good inductance matching, higher self-resonant frequency, and higher coupling coefficient by the fully symmetric interleaved architecture. This implies that the layout trace can be shortened to achieve the same inductance, thus smaller series resistance can be benefited. In addition, by the differential excitation of the fully symmetric 3-D architecture, the inductor Q can be improved by reducing the substrate loss [10]. And the most important of all, the chip area can be drastically reduced in contrast to their planar counterpart.

This paper is organized as follows. Section II presents the architecture of our proposed 3-D symmetric inductor and its lumped circuit model. Recently, inductor models on substrate loss and quality factor have drawn tremendous research efforts [14]-[20]. In this paper, a simple distributed capacitance model 


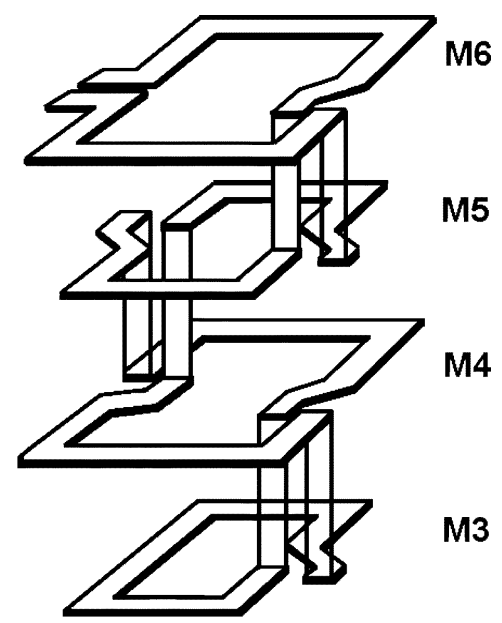

Fig. 2. Symmetric 3-D inductor structure.

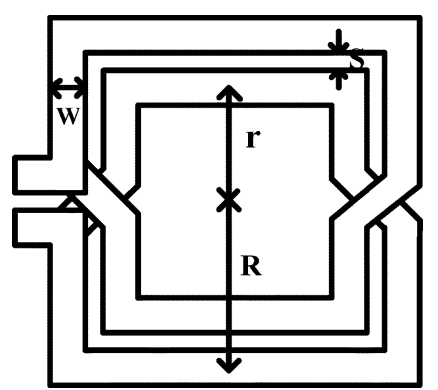

Fig. 3. Top view of a symmetric inductor.

(DCM) of the 3-D inductor is utilized to investigate its self-resonant frequency $\left(f_{\mathrm{SR}}\right)$ [22]. Their superiorities in $f_{\mathrm{SR}}$ over conventional planar architecture are validated by both the DCM and experimental results. Section III describes the applications of the 3-D inductor in a 3-D transformer design. To improve its coupling coefficient, a multi-layer, multi-turn transformer is proposed. Its self-resonant frequency is also investigated by a DCM model. The design of 3-D baluns and their characterizations are reported in Section IV. Finally, our conclusions are presented in Section V.

\section{3-D INDUCTOR}

Fig. 2 illustrates the proposed 3-D symmetric inductor architecture [21]. As a 4 turns example, the metal wire winds downward with a right-half turn on the upper layer interleaved with a left-half turn on the adjacent lower metal layer and vice versa. When the wire reaches the bottom layer, it winds upward along the counter path. In this way, the input and output port will be fully symmetric. To eliminate the parasitic capacitance between the adjacent metal layers, the outer radius of the loops on the adjacent layers are offset by the metal width, so that loops on M6, and M4 have the same radius, while that of loops on M5 and M3 is smaller.

The 3-D inductor can be characterized by the following design parameters, including the number of layers $n$, metal width $w$, inner radius $r$, outer radius $R$, and the metal spacing between adjacent wires $s$. Fig. 3 shows the top view of the inductor corresponding to the design parameters.
The self-resonant frequency $\left(f_{\mathrm{SR}}\right)$ of an inductor can be viewed as the frequency at which the peak magnetic $\left(E_{M}\right)$ and electric energy $\left(E_{E}\right)$ are equal, and can be determined by $f_{\mathrm{SR}}=\left(2 \pi \sqrt{C_{\mathrm{eq}} L_{\mathrm{eq}}}\right)^{-1}$, where $L_{\mathrm{eq}}$ and $C_{\mathrm{eq}}$ respectively represent the equivalent inductance and capacitance of the inductor. In the following, the $C_{\text {eq }}$ of both our proposed 3-D inductor and a planar inductor are analyzed utilizing a DCM [22] to investigate their $f_{\text {SR }}$ performance respectively.

For a given peak voltage of $V_{0}$ across the inductor and a stored electric energy of $\left(E_{E}\right)$ in the structure, the equivalent capacitance $C_{\text {eq }}$ can be calculated by [6], [22]

$$
E_{E}=\frac{1}{2} C_{\mathrm{eq}} V_{o}^{2}
$$

To derive the electric energy stored in the parasitic capacitors of the inductor, the following assumptions are made to simplify the derivations [5], [6], [22].

1) Voltage distribution is proportional to the length of the metal track.

2) The voltage potential is equal in half turn of the metal wire in the inductor and is determined by averaging the voltages of the previous half turn and the next one.

For an $n$ turns inductor, assume the lengths of each half turn are denoted as $l_{1}, l_{2}, \ldots, l_{2 n}$, the metal width is $W$, metal thickness is $T$, and the total length of the metal wire is $l_{T}=\sum_{k=1}^{2 n} l_{k}$

Define $d_{k}=1 / l_{T} \cdot \sum_{i=1}^{k} l_{i}$, the voltage profile of the inductor under a single ended stimulus can be described as

$$
V_{k}=V_{0} \times\left(1-d_{k}\right)
$$

Based on the above assumptions, the voltage of the $k$ th half turn of the inductor can be approximated as

$$
V(k)=\frac{1}{2}\left[V_{0} \times\left(1-d_{k-1}\right)+V_{0} \times\left(1-d_{k}\right)\right] .
$$

Fig. 4 displays the cross-sectional view of a planar inductor and its voltage profile. For a planar inductor, the major parasitic capacitance stems from the metal-to-substrate overlapped capacitance and the metal-to-metal side-wall capacitance. Let $C_{\mathrm{mts}, j}$ denote the unit capacitance of metal $j$ to substrate, which is a constant depending on the process [23], the electrical energy stored in the capacitor between the metal layer and the substrate can then be expressed as $E_{E 1, \mathrm{mts}}$, where

$$
E_{E 1, \mathrm{mts}}=\frac{1}{2} \sum_{k=1}^{2 n} C_{\mathrm{mts}, j} \cdot l_{k} \cdot W \cdot V(k)^{2}
$$

In addition, let $C_{\mathrm{msm}, j}$ denote the unit side-wall capacitance between the $k$ th and the $k+2$ th half turn on metal $j$, the electric energy stored in the side-wall parasitic capacitors between the metal layers can be expressed as $E_{E 1, \mathrm{mtm}}$, where

$$
E_{E 1, \mathrm{mtm}}=\frac{1}{2} \sum_{k=1}^{2 n-2} C_{\mathrm{msm}, j} \cdot l_{k} \cdot T \cdot[V(k)-V(k+2)]^{2}
$$



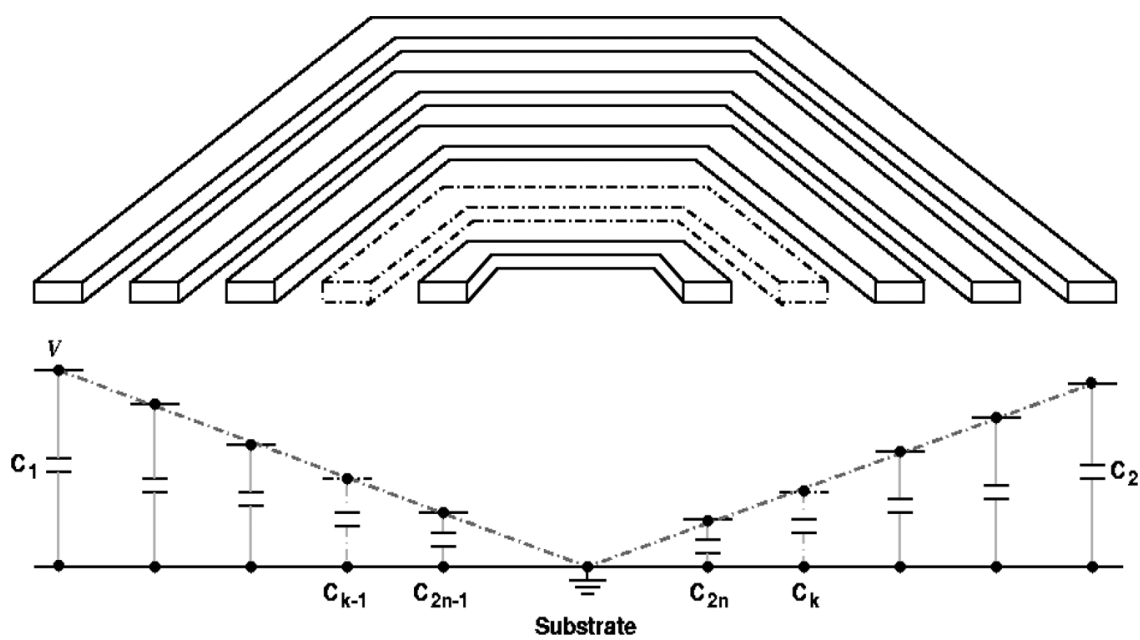

Fig. 4. Cross-sectional view and voltage profile of a planar inductor.

Combining (4) and (5), the total electric energy $\left(E_{E 1, \text { tot }}\right)$ stored in the structure can be derived as [22]

$$
E_{E 1, \mathrm{tot}}=E_{E 1, \mathrm{mts}}+E_{E 1, \mathrm{mtm}}=\frac{1}{2} C_{\mathrm{eq} 1} V_{0}^{2} .
$$

Thus, the effective parasitic capacitance of a planar inductor can be derived utilizing the DCM and expressed as $C_{\text {eq1 }}$, where

$C_{\mathrm{eq} 1} \approx \frac{1}{4} \sum_{k=1}^{2 n} C_{\mathrm{mts}, j} \cdot l_{k} \cdot W \cdot\left(2-d_{k-1}-d_{k}\right)^{2}$

$+\frac{1}{4} \sum_{k=1}^{2 n-2} C_{\mathrm{msm}, j} \cdot l_{k} \cdot T \cdot\left(d_{k+2}-d_{k}+d_{k+1}-d_{k-1}\right)^{2}$.

On the other hand, the cross-sectional view of the proposed 3-D inductor is shown in Fig. 5. For an n-turn, single turn per layer 3-D inductor, its major parasitic capacitance stems from the interlayer metal-to-metal and metal-to-substrate overlapped capacitance. Also, it can be seen that the metal-to-substrate capacitors exist in the bottom two metal layers only. Furthermore, since there is only one turn on a metal layer, the side-wall (fringing) capacitance is almost negligible.

Based on the same assumptions mentioned above, the electrical energy stored in the capacitor between the metal layer and the substrate can be expressed as $E_{E 2 \text {,mts }}$, where

$$
E_{E 2, \mathrm{mts}}=\frac{1}{2} \sum_{k=n-1}^{n+2} C_{\mathrm{mts}, j} \cdot l_{k} \cdot W \cdot V(k)^{2} .
$$

Besides, let $C_{\mathrm{mtm}, j}$ denote the unit metal-to-metal overlapped capacitance between the $k$ th and the $k+2$ th half turn on metal $j$, the electrical energy stored in the metal-to-metal parasitic capacitors can be represented as

$$
\begin{aligned}
E_{E 2, \mathrm{mtm}} & =\frac{1}{2}\left[\sum_{k=1}^{n-2} C_{\mathrm{mtm}, j} \cdot l_{k} \cdot W \cdot[V(k)-V(k+2)]^{2}\right. \\
+ & \left.\sum_{k=n+1}^{2 n-2} C_{\mathrm{mtm}, j} \cdot l_{k} \cdot W \cdot[V(k)-V(k+2)]^{2}\right]
\end{aligned}
$$

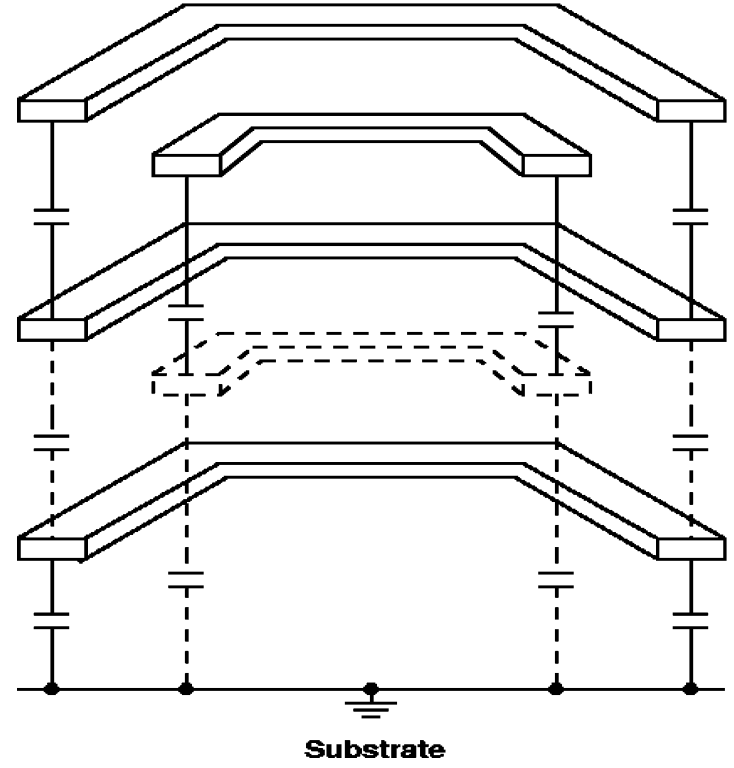

Fig. 5. Cross-sectional view of a 3-D transformer.

By taking both (8) and (9) into accounts, the total electric energy $\left(E_{E 2, \text { tot }}\right)$ stored in the structure utilizing DCM can be derived as

$$
E_{E 2, \mathrm{tot}}=\frac{1}{2} C_{\mathrm{eq} 2} V_{0}^{2}=E_{E 2, \mathrm{mts}}+E_{E 2, \mathrm{mtm}} .
$$

Thus, under a single-ended stimulus, the effective parasitic capacitance of the 3-D inductor can be expressed as $C_{\mathrm{eq} 2}$, where

$$
\begin{aligned}
C_{\mathrm{eq} 2} \approx & \frac{1}{4} \sum_{k=n-1}^{n+2} C_{\mathrm{mts}, j} \cdot l_{k} \cdot W \cdot\left(2-d_{k}-d_{k-1}\right)^{2} \\
& +\frac{1}{4} \sum_{k=1}^{n-2} C_{\mathrm{mtm}, j} \cdot l_{k} \cdot W \\
& \cdot\left(d_{k+2}-d_{k}+d_{k+1}-d_{k-1}\right)^{2} \\
& +\frac{1}{4} \sum_{k=n+1}^{2 n-2} C_{\mathrm{mtm}, j} \cdot l_{k} \cdot W \\
& \cdot\left(d_{k+2}-d_{k}+d_{k+1}-d_{k-1}\right)^{2} .
\end{aligned}
$$


TABLE I

PERFORMANCE COMPARISONS OF PlANAR SYMMETRIC, 3-D ASYMMETRIC AND 3-D SYMMETRIC INDUCTOR

\begin{tabular}{|c|c|c|c|c|c|}
\hline$r=45 \mu \mathrm{m}$ & $\mathrm{n}$ & 3 & 4 & 5 & 6 \\
\hline \multirow{3}{*}{ Planar symmetric inductor } & $\mathrm{L}(\mathrm{nH})$ & 1.56 & 2.6 & 4.65 & 6.25 \\
\hline & $\mathrm{f}_{\mathrm{SR}}(\mathrm{GHz})$ & 19.3 & 14.5 & 11.7 & 8.4 \\
\hline & $Q(\max )$ & 7.4 & 6.9 & 6.2 & 5.3 \\
\hline \multirow{3}{*}{ 3-D asymmetric inductor [6] } & $\mathrm{L}(\mathrm{nH})$ & 1.6 & 2.74 & 4.5 & 6.3 \\
\hline & $\mathrm{f}_{\mathrm{SR}}(\mathrm{GHz})$ & 25.2 & 18.4 & 14.7 & 11.2 \\
\hline & $\mathrm{Q}(\max )$ & 6.1 & 5.25 & 4.8 & 4.15 \\
\hline \multirow{3}{*}{ Proposed 3-D symmetric } & $\mathrm{L}(\mathrm{nH})$ & 1.64 & 2.7 & 4.44 & 6.1 \\
\hline & $\mathrm{f}_{\mathrm{SR}}(\mathrm{GHz})$ & 31 & 21.5 & 15.4 & 12.5 \\
\hline & $\mathrm{Q}(\max )$ & 5.7 & 4.7 & 4.35 & 4.05 \\
\hline$\frac{A_{3 D}}{A_{\text {planar }}}$ & $\begin{array}{l}\text { 3-D Symmetric / } \\
\text { Asymmetric Inductor }\end{array}$ & $70 \%$ & $52 \%$ & $40 \%$ & $32 \%$ \\
\hline
\end{tabular}

Since the equivalent inductance $L_{\mathrm{eq}}$ of an inductor can be derived as

$$
L_{\mathrm{eq}}=\sum_{i=1}^{n} L_{i}+M
$$

where $L_{i}$ represents the inductance on each loop, and $M$ represents the summation of mutual inductances, the self-resonant frequency can be derived as

$$
f_{\mathrm{SR}}=\frac{1}{2 \pi \sqrt{L_{\mathrm{eq}} C_{\mathrm{eq}}}} .
$$

Thus an inductor structure with a smaller $C_{\mathrm{eq}}$ would manifest a higher $f_{\mathrm{SR}}$. Compare (7) with (11), although our proposed 3-D inductors suffer from metal-to-metal overlapped capacitance, the impacts of the parasitic capacitance can be alleviated by increasing the distance between the metal plates (offset the diameters of the adjacent loops), and minimizing the electrical potential between the top and bottom plates (by the twisted and interleaved architecture). On the other hand, in contrast to a planar counterpart, no metal-to-metal side-wall capacitance exists in the proposed one turn per layer architecture. The side-wall parasitic capacitance would become significant in the deep submicron technology [22]. Thus, the effective parasitic capacitance $\left(C_{\mathrm{eq}}\right)$ of the 3-D inductor can be reduced, resulting in a better self-resonant frequency $\left(f_{\mathrm{SR}}\right)$.

Table I summarizes the performance comparisons between planar symmetric inductors, conventional 3-D asymmetric inductors in [6], and our proposed 3-D symmetric inductors by EM simulation. With the same inner loop diameter $(r)$, metal width $(w)$, metal spacing $(s)$, and about the same inductance, the 3-D inductors (for both the symmetric and asymmetric ones) manifest a higher self-resonant frequency in all cases by self shielding, and the most important of all, the chip area can be reduced by $32 \%$ to $70 \%$. Besides, the quality factors for the symmetric and asymmetric 3-D inductors are about the same.

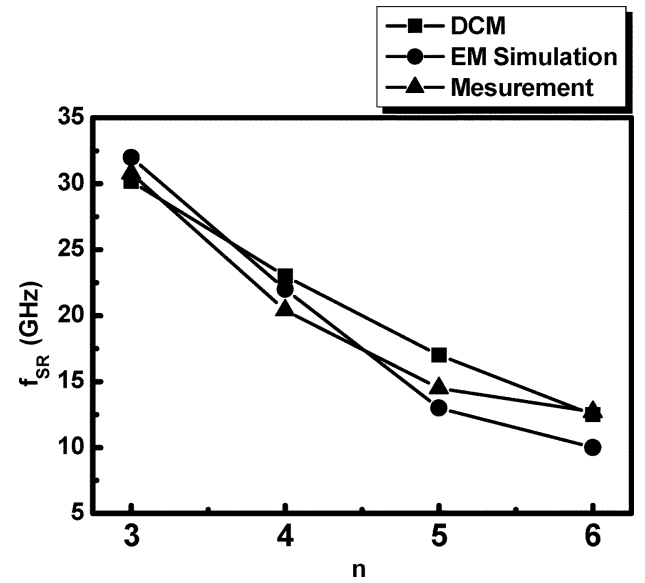

Fig. 6. $f_{\mathrm{SR}}$ performance comparison of 3-D inductor (by DCM model, EM simulation, and measurement).

In contrast to a planar inductor which is mainly composed of the top (thickest) metal, the series resistance of the 3-D inductors increases due to via connections and employing the lower (thinner) metal layers. Thus, the quality factor is degraded (by less than 2).

Fig. 6 illustrates the experimental results on the self-resonant frequency $\left(f_{\mathrm{SR}}\right)$ v.s. number of turns $(n)$ for the 3-D inductors. All the components are fabricated in a $0.18-\mu \mathrm{m}$ standard CMOS technology, and have an outer radius $(R)$ of $45 \mu \mathrm{m}$. The $f_{\mathrm{SR}}$ estimated by (11) are well agreed with simulations (by EM-tools) and measurement results for various numbers of turns $(n)$. According to the simulation result, a 3-turns 3-D symmetric inductor has a self-resonant frequency as high as $30 \mathrm{GHz}$. It reveals that by both offsetting the diameters of adjacent loops and the interleaving voltage profile, the effective parasitic capacitance of the 3-D inductors can be significantly reduced, thus a high $f_{\mathrm{SR}}$ can be benefited.

Fig. 7 shows the distributed circuit model of a 4-turn 3-D inductor. Here, $\left(R_{1}-R_{4}\right)$ and $\left(R_{5}-R_{8}\right)$ respectively represent the distributed resistance of $L_{1}$ and $L_{2} . M_{\mathrm{mn}}$ represents the distributed mutual inductance between the $m$ th and the $n$th half 


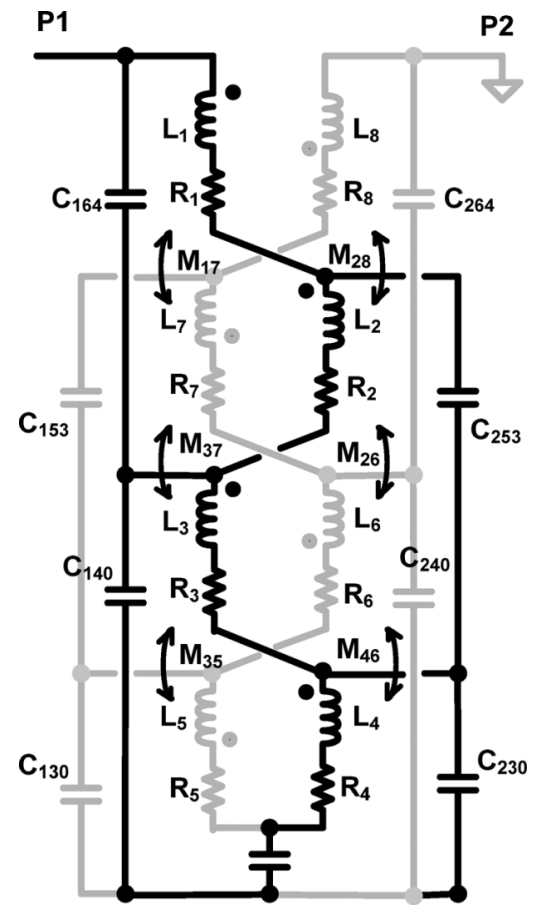

Fig. 7. Distributed circuit model of 3-D inductor.

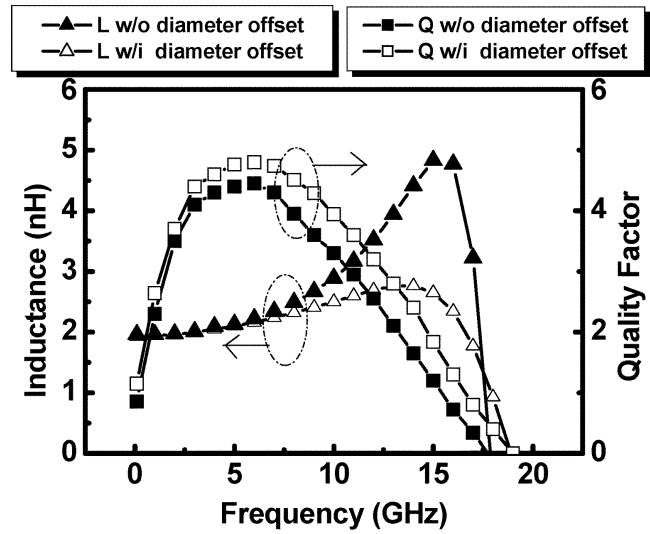

Fig. 8. Simulated inductance and quality factor of single-turn-4-layers architecture with and without diameter offset (inner radius $r=38.5 \mu \mathrm{m}$, metal width $w=10 \mu \mathrm{m}$, spacing $s=1.5 \mu \mathrm{m})$.

turn of the 3-D inductor ( $m=1,2,3,4 ; n=5,6,7,8$ ). $\mathrm{C}_{1 j k}$ and $\mathrm{C}_{2 j k}$ denote the distributed overlapping capacitance between metal layer $(j=3,4,5,6 ; k=3,4)$ and substrate $(k=0)$.

Fig. 8 shows the simulated inductance and quality factor of the 3-D inductors with and without diameters offset of the adjacent loops. It can be seen that both the quality factor and the self-resonant frequency of the proposed architecture (with diameter offset) can be improved.

The 3-D inductors occupy a smaller chip area and manifest an improved self-resonant frequency at the expense of a poorer quality factor. In contrast to a planar inductor which is mainly composed of the top (thickest) metal, the series resistance of the 3-D inductors increases due to via connections and employing the lower (thinner) metal layers. The metal thickness is about $2 \mu \mathrm{m}$ for the top layer metal and is only $0.53 \mu \mathrm{m}$ for the bottom layer metal in this technology. To improve the quality factor,

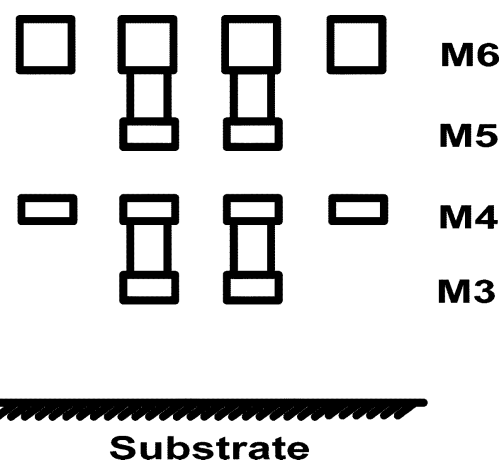

Fig. 9. Cross-sectional view of a symmetric 3-D inductor with IMLS.

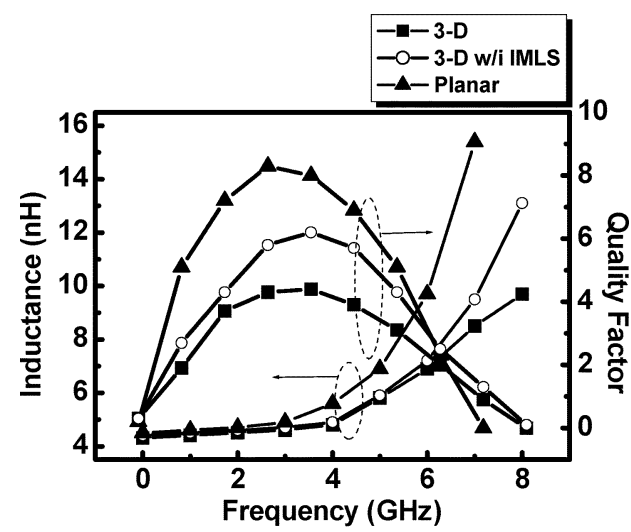

Fig. 10. $Q$ comparison of planar, 3-D, and 3-D with IMLS inductors.

improved multi-level shunt (IMLS) techniques can be adopted [10]. Fig. 9 shows the cross-sectional view of the 3-D inductor with IMLS. As the radii of the loops on the adjacent metal layers are different, the effective trace thickness can be increased by the shunting metal layer. Besides, to avoid severely degrading its self-resonant frequency, the IMLS is only utilized in the inner loops to compromise between the parasitic capacitance and the series resistance.

Fig. 10 shows the quality factor comparisons of a planar symmetric and a 3-D symmetric inductor by simulation. Here the inner loops of the IMLS inductor is composed of two metal layers shunting together, as is shown in Fig. 9, while the planar inductor utilizes only the top layer metal. All the inductors have the same inductance of $4.5 \mathrm{nH}, 4$ turns, $w=10 \mu \mathrm{m}, s=$ $1.5 \mu \mathrm{m}$ and inner radius $r$ of $65 \mu \mathrm{m}$. The planar and 3-D inductors respectively occupy a chip area of $209 \times 209 \mu \mathrm{m}^{2}$ and $163 \times 163 \mu \mathrm{m}^{2}$. According to simulation results, it can be seen that the peak quality factor of the planar inductor is the best (higher than that of the IMLS 3-D inductor by 2), while the quality factor of the 3-D inductor can be increased by 2 utilizing IMLS.

The superiorities of the proposed 3-D inductors in area consumption are further investigated for equivalent inductor $(L)$ and quality factor $(Q)$ with respect to their planar variants. Here the planar inductors are laid-out by either reducing the metal width $w$ (planar I) or reducing the inner loop radius $r$ (planar II). According to EM-simulation results, the performance comparisons are summarized in Table II. In both cases, the total length of the metal wire is about the same to have the same inductance. Thus, 
TABLE II

Performance Comparisons of Planar and 3-D Inductors With Equal $L$ and $Q$

\begin{tabular}{|c|c|c|c|c|c|c|c|c|c|}
\hline \multicolumn{2}{|c|}{ Architecture } & $\begin{array}{c}\text { Total } \\
\text { Length }\end{array}$ & $\mathrm{L}$ & $\begin{array}{c}\mathrm{Q} \\
(\max )\end{array}$ & $\begin{array}{c}\text { Metal } \\
\text { Width }\end{array}$ & $\begin{array}{c}\text { Metal } \\
\text { Spacing }\end{array}$ & $\begin{array}{c}\text { Inner } \\
\text { Radius }\end{array}$ & $\mathrm{f}_{\mathrm{SR}}$ & $\begin{array}{c}\text { Area } \\
(\mu \mathrm{m} \times \mu \mathrm{m})\end{array}$ \\
\hline 3-D & $\begin{array}{c}\text { 1-turn- } \\
\text { 3-layers }\end{array}$ & $\begin{array}{c}1200 \\
\mu \mathrm{m}\end{array}$ & $1.74 \mathrm{nH}$ & 6.2 & $10 \mu \mathrm{m}$ & $1.5 \mu \mathrm{m}$ & $40 \mu \mathrm{m}$ & $\begin{array}{c}20 \\
\mathrm{GHz}\end{array}$ & $\begin{array}{c}66 \% \\
100 \times 100\end{array}$ \\
\hline Planar I & $\begin{array}{c}3.7 \\
\text { turns }\end{array}$ & $\begin{array}{c}1194 \\
\mu \mathrm{m}\end{array}$ & $1.72 \mathrm{nH}$ & 6.28 & $5 \mu \mathrm{m}$ & $1.5 \mu \mathrm{m}$ & $40 \mu \mathrm{m}$ & $\begin{array}{c}13.5 \\
\mathrm{GHz}\end{array}$ & $\begin{array}{c}94 \% \\
(119 \times 119)\end{array}$ \\
\hline $\begin{array}{c}\text { Planar } \\
\text { II }\end{array}$ & 3.5 turns & $\begin{array}{c}1196.5 \\
\mu \mathrm{m}\end{array}$ & $1.73 \mathrm{nH}$ & 6.55 & $10 \mu \mathrm{m}$ & $1.5 \mu \mathrm{m}$ & $23 \mu \mathrm{m}$ & $\begin{array}{c}17.1 \\
\mathrm{GHz}\end{array}$ & $\begin{array}{c}100 \% \\
(123 \times 123)\end{array}$ \\
\hline
\end{tabular}

the number of turns is increased in the planar inductors for a reduced metal width or a reduced inner radius (3.7 turns for planar I and 3.5 turns for planar II). It turns out that the chip area saving in both cases becomes insignificant, while the $f_{\mathrm{SR}}$ of the planar inductors is still worse than that of the 3-D inductor. The main reason for the $f_{\mathrm{SR}}$ degradation is due to the fact that the increment of the side-wall capacitance (as the number of turns is increased) overwhelms the reduction of the metal-to-substrate capacitance in this technology.

\section{3-DIMENSINAL TRANSFORMER}

\section{A. 1 Turn per Layer 3-D Transformer}

A 1:1, 3-D fully symmetric transformer can be easily built up by center-tapping the middle point of a 3-D symmetric inductor to a common mode voltage or ground, as is shown in Fig. 11(a). Fig. 11(b) depicts the symbol view, where an inverting type transformer bridges port 1 and port 2. The magnetic coupling mainly stems from conductor loops on the adjacent layers.

The voltage profile of a 3-D inductor under single-ended stimulus is different from that of differential excitation. For an $n$ turns, single turn per layer transformer, the voltage profile of the transformer under differential stimulus is modified to

$$
V_{k}=V_{0} \times\left(1 / 2-d_{k}\right)
$$

and the voltage of the $k$ th half turn of the inductor can be approximated as

$$
V(k)=\frac{1}{2}\left[V_{0} \times\left(\frac{1}{2}-d_{k-1}\right)+V_{0} \times\left(\frac{1}{2}-d_{k}\right)\right] .
$$

Thus, the effective parasitic capacitance of the 3-D transformer under differential excitation can be expressed as $C_{\text {eq3 }}$, where

$$
\begin{aligned}
C_{\mathrm{eq} 3} \approx & \frac{1}{4} \sum_{k=n-1}^{n+2} C_{\mathrm{mts}, j} \cdot l_{k} \cdot W \cdot\left(1-d_{k}-d_{k-1}\right)^{2} \\
& +\frac{1}{4} \sum_{k=1}^{n-2} C_{\mathrm{mtm}, j} \cdot l_{k} \cdot W \\
& \cdot\left(d_{k+2}-d_{k}+d_{k+1}-d_{k-1}\right)^{2} \\
& +\frac{1}{4} \sum_{k=n+1}^{2 n-2} C_{\mathrm{mtm}, j} \cdot l_{k} \cdot W \\
& \cdot\left(d_{k+2}-d_{k}+d_{k+1}-d_{k-1}\right)^{2}
\end{aligned}
$$

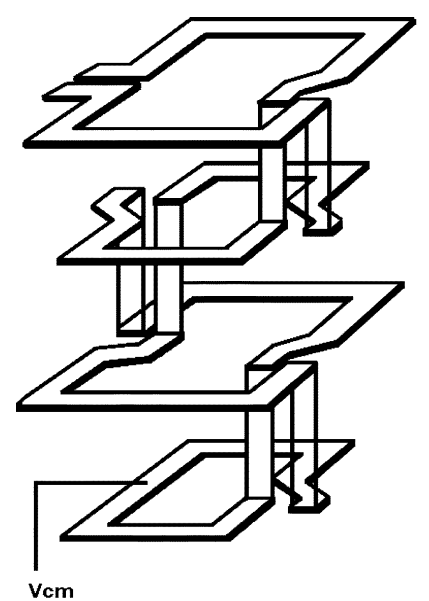

(a)

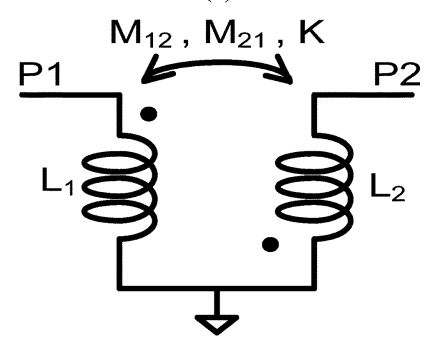

(b)

Fig. 11. (a) 1:1 3-D transformer. (b) Symbol view.

Compare (16) with (11), since the effective capacitance between the metal to the substrate is reduced, a 3-D inductor under differential stimulus manifests a higher self-resonant frequency. Fig. 12 illustrates the simulated quality factor of the singleturn-4-layers 3-D inductors (Inner radius $r=38.5 \mu \mathrm{m}$, metal width $w=10 \mu \mathrm{m}$, spacing $s=1.5 \mu \mathrm{m}$ ) under single-ended and differential stimuli. It reveals that both the quality factor and $f_{\mathrm{SR}}$ can be improved by differentially driving the transformer.

The self-inductance $\left(L_{1}, L_{2}\right)$, mutual inductance $\left(M_{12} M_{21}\right)$, and coupling coefficient $(K)$ of the 1:13-D transformer is characterized as

$$
\begin{aligned}
L_{1} & =\frac{\operatorname{Imag}(Z(1,1))}{2 \pi f} \quad L_{2}=\frac{\operatorname{Imag}(Z(2,2))}{2 \pi f} \\
M_{21} & =\frac{\operatorname{Imag}(Z(2,1))}{2 \pi f} \quad M_{12}=\frac{\operatorname{Imag}(Z(1,2))}{2 \pi f} \\
K & =\frac{M_{21}}{\sqrt{L_{1} L_{2}}}=\frac{M_{12}}{\sqrt{L_{1} L_{2}}}\left(M_{12}=M_{21}\right)
\end{aligned}
$$

where $\operatorname{Imag}(Z(m, n))$ is the imaginary part of the $Z$ parameters measured by network analyzer. 


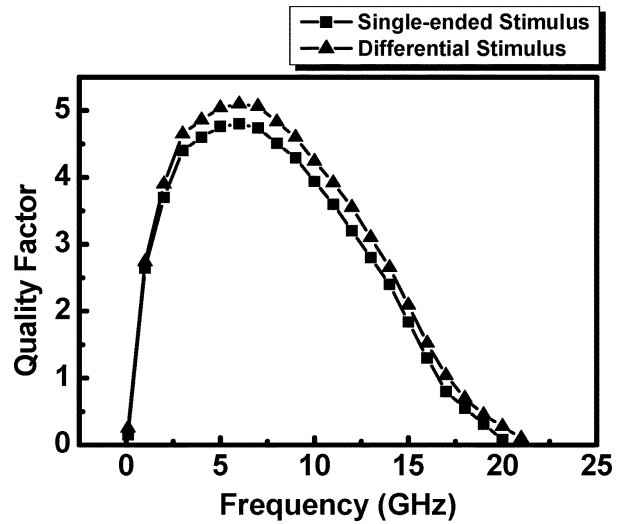

Fig. 12. Simulated quality factor of a single-turn-4-layers inductor under single-ended and differential stimuli (inner radius $r=38.5 \mu \mathrm{m}$, metal width $w=10 \mu \mathrm{m}$, spacing $s=1.5 \mu \mathrm{m}$ ).

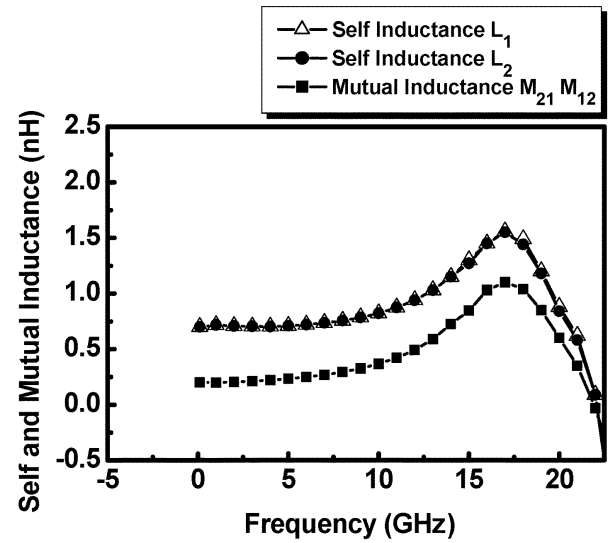

(a)

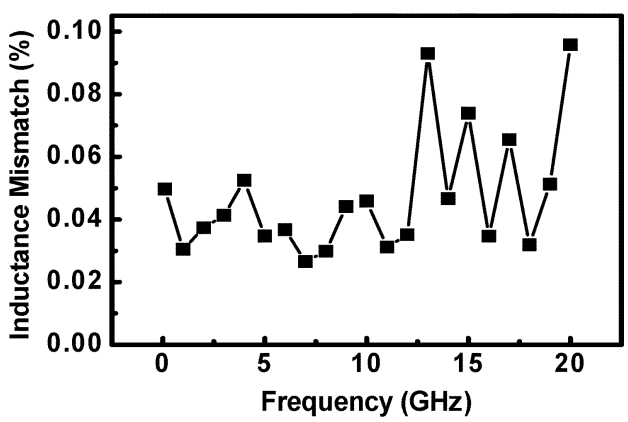

(b)

Fig. 13. (a) Measured self and mutual inductance. (b) Inductance mismatch.

Fig. 13 shows the measured performance of a test kit with an inner diameter $r=38.5 \mu \mathrm{m}, w=10 \mu \mathrm{m}, s=1.5 \mu \mathrm{m}$, 4 turns, and single turn per layer architecture. The inductance in each branch is about $0.75 \mathrm{nH}$. The mutual coupling coefficient of the transformer ranges from 0.3 to 0.7 , which increases along with the increments of operating frequency. The inductance mismatches between the two branches are less than $0.1 \%$ within $20-\mathrm{GHz}$ range, which demonstrates that the architecture is perfect in symmetry.

The effectiveness of the DCM in evaluating the $f_{\mathrm{SR}}$ of 3-dimensional transformers has been verified by experimental results. Fig. 14 illustrates the $f_{\mathrm{SR}}$ performance estimated by the DCM, simulated by an EM tool, and by measurement for 1 turn per layer transformers. In all cases the DCM model described

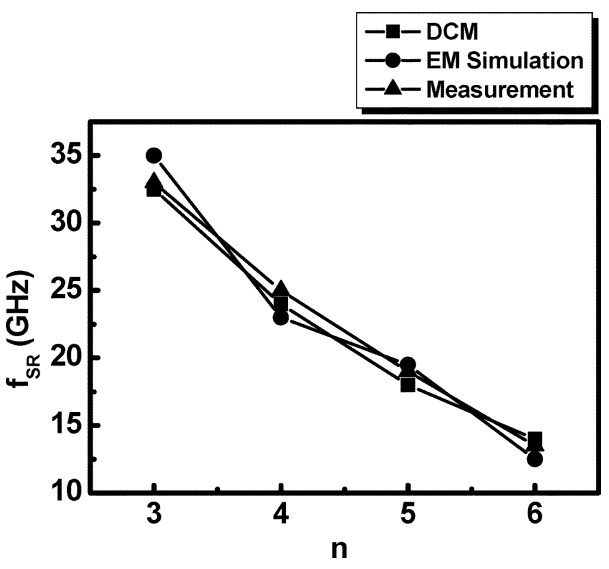

Fig. 14. $f_{\mathrm{SR}}$ performance comparison of 3-D transformer (by DCM model, EM simulation, and measurement).

in (16) provide a convenient and fairly accurate way in evaluating $f_{\mathrm{SR}}$ performance. Also, the $f_{\mathrm{SR}}$ of a differentially driven transformer shown in Fig. 14 is better than that of a single-ended driven inductor which is shown in Fig. 6.

\section{B. 2 Turn per Layer 3-D Transformer}

To further improve the coupling coefficient of the 3-D transformer, a two turn per layer architecture is proposed [24], as is shown in Fig. 15(a). Compared to its one turn per layer counterpart, the mutual coupling coefficient is enhanced by increasing both the magnetic coupling on the same metal layer and the adjacent metal layer.

The distributed circuit model of the 2 turns two layer transformer is shown in Fig. 15(b), where $R_{i}$, and $L_{i}(\mathrm{i}=1 \sim 8)$ respectively represent the distributed resistance and inductance, $M_{\mathrm{mn}}$ represents the distributed mutual inductance between the $m$ th and the $n$th half turn of the 3-D transformer $(\mathrm{m}=1,2$, $3,4 ; \mathrm{n}=5,6,7,8) . C_{1 j k}$, and $C_{2 j k}$ denote the metal-to-metal overlapped capacitance ( $\mathrm{j}=6, \mathrm{k}=5)$, and $C_{1 x x}$, and $C_{2 y y}$ denote the side-wall fringing capacitance $(x, y=5,6)$.

For a $2 n$ turns, 2 turns per layer transformer, define

$$
d_{k}=\frac{\sum_{i=1}^{k} l_{i}}{\sum_{i=1}^{4 n} l_{i}} .
$$

Based on the DCM mentioned above, the total electric energy $\left(E_{E 4, \text { tot }}\right)$ stored in the structure utilizing DCM can be derived as

$$
\begin{aligned}
E_{E 4, \mathrm{tot}}= & E_{E 4, \mathrm{mts}}+E_{E 4, \mathrm{msm}}+E_{E 4, \mathrm{mtm}} \\
= & \frac{1}{2} \sum_{k=n}^{n+1} C_{\mathrm{mts}}(j) \cdot l_{k} \cdot W \cdot\left\{[V(k)]^{2}+[V(3 k)]^{2}\right\} \\
& +\frac{1}{2} \sum_{k=1}^{2 n} C_{\mathrm{msm}}(j) \cdot l_{k} \cdot T \cdot[V(k)-V(k+2 n)]^{2} \\
& +\frac{1}{2} \sum_{i=0, i \neq n-1}^{2 n-2} \sum_{k=1}^{2} C_{\mathrm{mtm}}(j) \cdot l_{k} \cdot W \\
& \cdot[V(k+i)-V(k+4 n-2-i)]^{2} .
\end{aligned}
$$




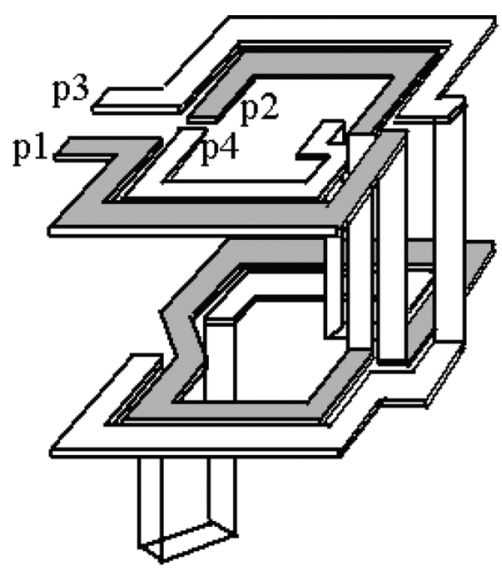

(a)

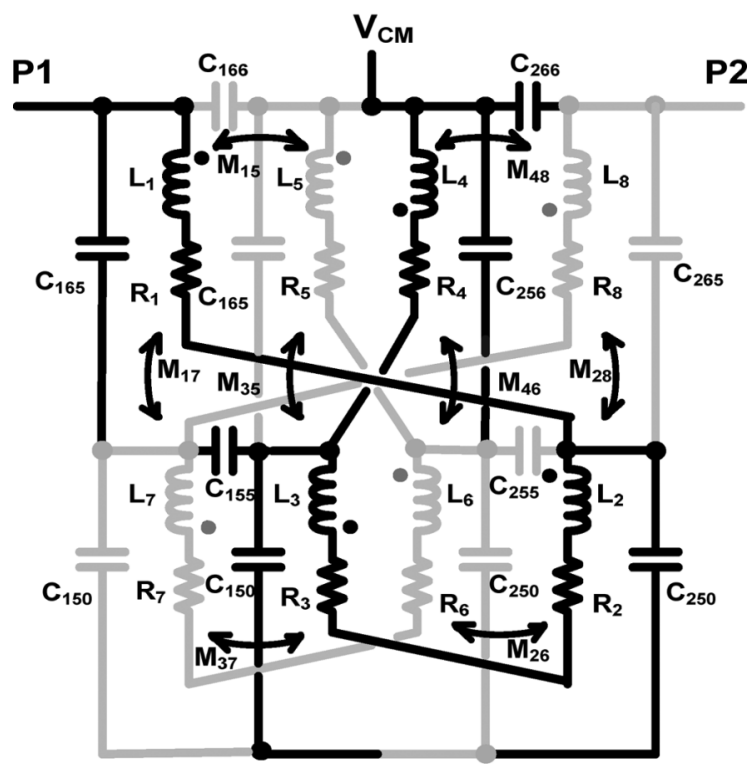

(b)

Fig. 15. (a) Symmetric 3-D transformer. (b) Circuit model of a 2 turns per layer transformer.

Thus the effective parasitic capacitance of a $2 n$-turns- $n$ -layers transformer under differential excitation can be derived as $C_{\text {eq } 4}$, where

$$
\begin{aligned}
\mathrm{C}_{\mathrm{eq} 4} \approx & \frac{1}{4} \sum_{k=n}^{n+1} C_{\mathrm{mts}}(j) \cdot l_{k} \cdot W \\
& \cdot\left\{\left[1-d_{k-1}-d_{k}\right]^{2}+\left[1-d_{3 k-1}-d_{3 k}\right]^{2}\right\} \\
& +\frac{1}{4} \sum_{k=1}^{2 n} C_{\mathrm{msm}}(j) \cdot l_{k} \cdot T \\
& \cdot\left[d_{k+2 n}+d_{k+2 n-1}-d_{k}-d_{k-1}\right]^{2} \\
& +\frac{1}{4} \sum_{i=0, i \neq n-1}^{2 n-2} \sum_{k=1}^{2} C_{\mathrm{mtm}}(j) \cdot l_{k} \cdot W \\
& \cdot\left[d_{k+4 n-2-i}+d_{k+4 n-3-i}-d_{k+i}-d_{k+i-1}\right]^{2}
\end{aligned}
$$

Compare (19) with (16), the parasitic capacitances between the two ports are increased in contrast to that of a single turn per layer architecture. This implies that the insertion loss of a multi-turn per layer 3-D transformer can be reduced with the aid of electrical coupling in addition to magnetic coupling. On

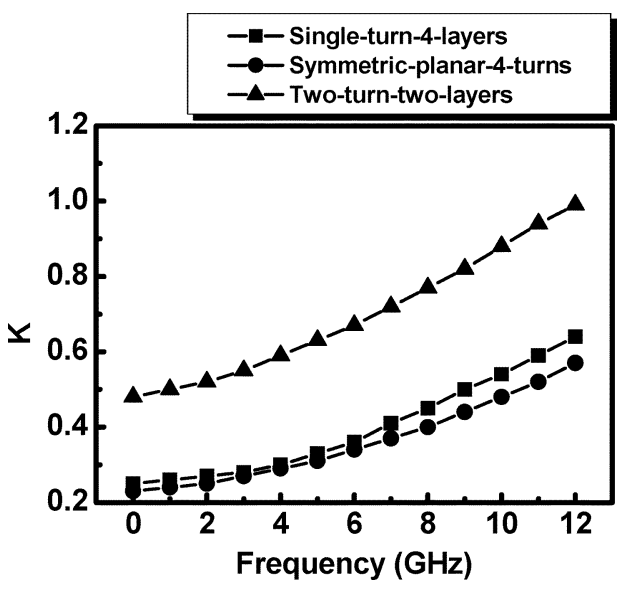

Fig. 16. Measured coupling coefficient $k$.

the other hand, the self-resonant frequency would be suffered. This view point is verified by measurement results.

Fig. 16 illustrates the coupling coefficients of a single-turn per layer (4 turns), a two turns two layers, and a planar 4 turns transformer. With the same inductance in each branch $(1 \mathrm{nH})$, the measured coupling coefficient of the two turn two layer transformer is up to 0.77 at $8 \mathrm{GHz}$, while the coupling coefficients for the single turn 4 layers (3-D) and single layer four turns (planar) architectures are about the same $(0.4 \sim 0.45)$. Moreover, the chip areas for the 3-D structures are only 52\% smaller compared to their planar counterpart. On the other hand, the self-resonant frequencies of a single turn per layer (4 layers), a two turns per layer (2 layers), and a 4 turns planar transformer are 24, 12.1, and $16.5 \mathrm{GHz}$, respectively. The performance benchmark is summarized in Table III. By improving the magnetic coupling and introducing electric coupling in the 3-D multi-turn per layer transformer, it is beneficial when the transformer is utilized as an ac-coupled device.

Fig. 17 shows the measured insertion loss of the transformer between the input and output ports. By a 4 turn, 2 turns per layer architecture, the insertion loss can be improved to be less than $-3 \mathrm{~dB}$. The $f_{\mathrm{SR}}$ performances of various inductors and transformers are summarized in Table IV. Also, the DCM models derived in (7), (11), (16), and (19) are applied in evaluating their $f_{\text {SR }}$ respectively. Compared to the experimental results, the prediction errors are within $3 \%$ to $10 \%$.

\section{3-D BALUN}

A 3-D balun (balance to unbalance converter) can be built up by interleaving one symmetric inductor with one symmetric transformer. Fig. 18 depicts the corresponding layout topology and the symbol view. For an $R=100 \mu \mathrm{m}, w=10 \mu \mathrm{m}, s=$ $1.5 \mu \mathrm{m}, 3$ turns/6 layers balun, the measured insertion loss $\left(S_{21}\right.$ and $S_{31}$ ), gain mismatches, and phase mismatches are illustrated in Fig. 19(a)-(c), respectively. In this prototype, a single turn per layer topology is used, thus the mutual coupling mainly stems from layer to layer magnetic coupling. The insertion loss within the $6 \sim 10-\mathrm{GHz}$ frequency band is less than $5 \mathrm{~dB}$, which can be further improved by increasing the number of loops per layer. The 3-D balun manifests less than $0.6-\mathrm{dB}$ gain mismatch and $7^{\circ}$ phase error for $10-\mathrm{GHz}$ frequency range. 
TABLE III

PERFORMANCE BENCHMARK

\begin{tabular}{|c|c|c|c|c|c|}
\hline $\mathrm{W}=10 \mathrm{um}$ & $\mathrm{L} 1 / \mathrm{L} 2 / \mathrm{M} 21(\mathrm{nH})$ & $\mathrm{Q} 1 / \mathrm{Q} 2(\mathrm{max})$ & $f_{S R}$ & $\mathrm{~K}$ & $\mathrm{Area}$ \\
\hline $\begin{array}{c}\text { Single-turn-4-layers } \\
\text { transformer } \\
(\mathrm{r}=38.5 \mathrm{um})\end{array}$ & $0.76 / 0.75 / 0.34 @ 8 \mathrm{GHz}$ & $4.7 / 4.6 @ 11 \mathrm{GHz}$ & $24 \mathrm{GHz}$ & $0.45 @ 8 \mathrm{GHz}$ & $52 \%$ \\
\hline $\begin{array}{c}2 \text {-turn-2-layers } \\
\text { transformer } \\
(\mathrm{r}=27 \mathrm{um})\end{array}$ & $0.62 / 0.61 / 0.48 @ 8 \mathrm{GHz}$ & $4.3 / 4.2 @ 8.5 \mathrm{GHz}$ & $12.1 \mathrm{GHz}$ & $0.77 @ 8 \mathrm{GHz}$ & $52 \%$ \\
\hline $\begin{array}{c}\text { Symmetric planar } \\
\text { 4-turns } \\
\text { transformer } \\
(\mathrm{r}=38.5 \mathrm{um})\end{array}$ & $0.8 / 0.79 / 0.32 @ 8 \mathrm{GHz}$ & $6.2 / 6.3 @ 10 \mathrm{GHz}$ & $16.5 \mathrm{GHz}$ & $0.4 @ 8 \mathrm{GHz}$ & $100 \%$ \\
\hline
\end{tabular}

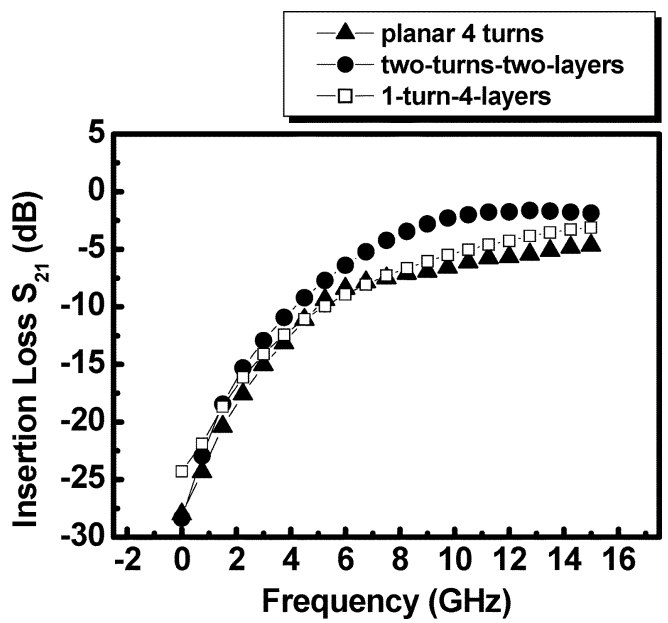

Fig. 17. Coupling loss of the transformer in two port network.

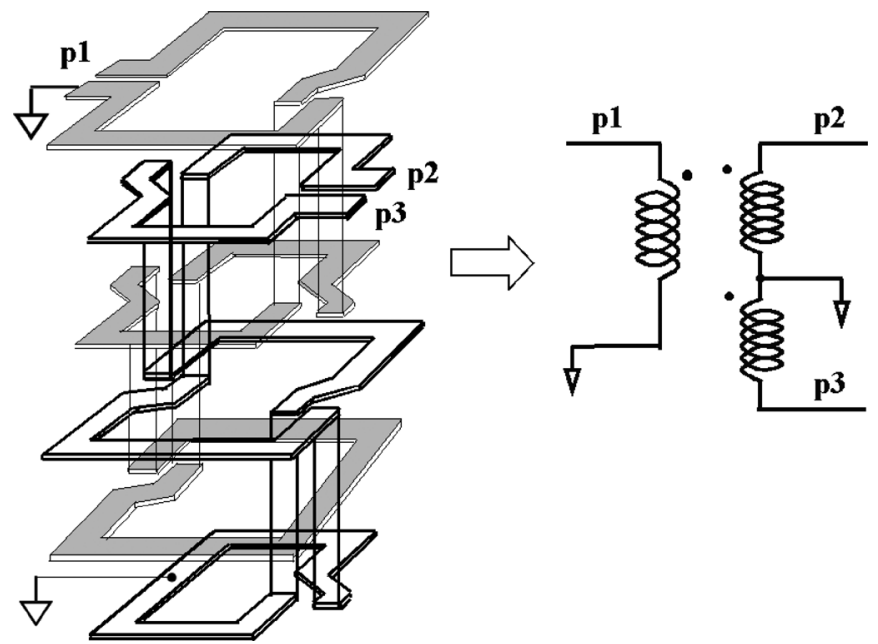

Fig. 18. Proposed symmetric 3-D balun. (a) Layout topology. (b) Symbol view.

Table V shows the performance comparison between the proposed 3-D balun and its planar counterpart by EM tool simulations. For an $r=27 \mu \mathrm{m}, w=10 \mu \mathrm{m}, s=1.5 \mu \mathrm{m}$, and 6 turns architecture ( 3 turns for both the primary and secondary port), the proposed 3-D balun manifests a lower insertion loss, a better gain and phase matching performance, a much higher self-resonant frequency, and the chip area is only $28 \%$ smaller, while the quality factor degradation is less than $1.5 \mathrm{in}$ a $10-\mathrm{GHz}$ frequency range.

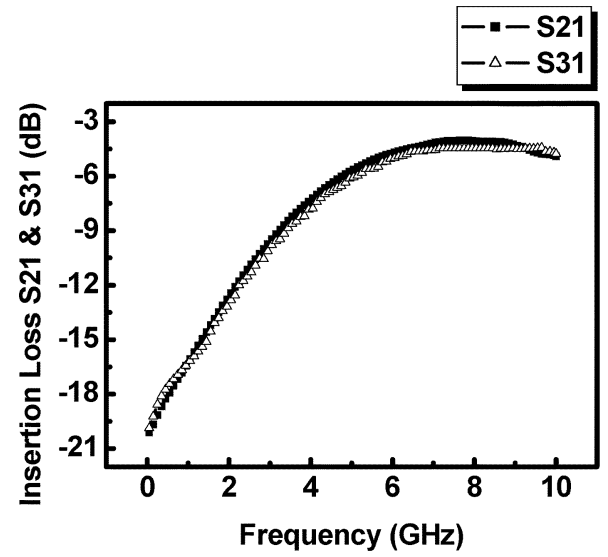

(a)

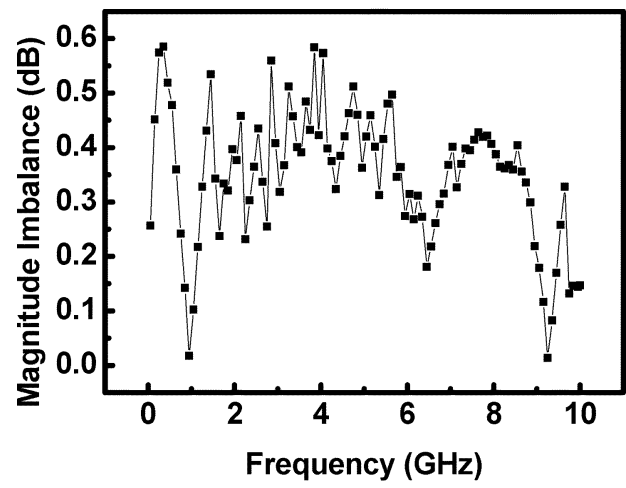

(b)

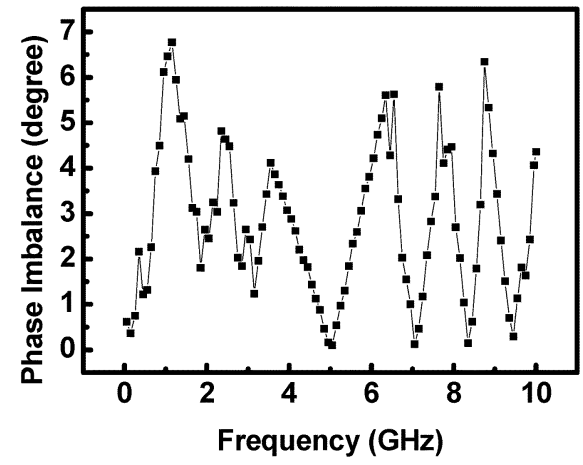

(c)

Fig. 19. 3D balun measurement results. (a) $S_{21}$ and $S_{31}$ gain response (insertion loss) (dB). (b) Gain mismatch (dB). (c) Phase mismatch (degree).

\section{CONCLUSION}

This paper presents novel miniaturized 3-D symmetric passive components, including inductors, transformers, and baluns 
TABLE IV

$f_{\text {SR }}$ COMPARISONS (DCM v.S. MEASUREMENT RESULTS)

\begin{tabular}{|c|c|c|c|c|c|c|c|}
\hline Architecture & $\begin{array}{c}L_{e q} \\
(\mathrm{nH})\end{array}$ & $\begin{array}{c}C_{e q}(\mathrm{fF}) \\
\text { by DCM }\end{array}$ & $\begin{array}{c}f_{S R} \\
\text { by DCM }\end{array}$ & $\begin{array}{c}f_{S R} \\
\text { Measured }\end{array}$ & $\begin{array}{c}\text { Quality factor } \\
\text { Chip area }\end{array}$ & $\begin{array}{c}\text { Prediction } \\
\text { Error }\end{array}$ \\
\hline $\begin{array}{c}\text { Symmetric-planar- } \\
\text { 4-turns inductor }(\mathrm{r}=38.5 \mu \mathrm{m})\end{array}$ & 2 & $51.4\left(C_{e q 1}\right)$ & $15.7 \mathrm{GHz}$ & $16.5 \mathrm{GHz}$ & 6.9 & $\begin{array}{c}100 \% \\
139 \times 139\end{array}$ \\
\hline $\begin{array}{c}\text { Single-turn- } \\
\text { 4-layers inductor }(\mathrm{r}=38.5 \mu \mathrm{m})\end{array}$ & 2 & $23.96\left(C_{e q 2}\right)$ & $23 \mathrm{GHz}$ & $21 \mathrm{GHz}$ & 4.6 & $\begin{array}{c}5 \% \\
100 \times 100\end{array}$ \\
\hline $\begin{array}{c}\text { Single-turn- } \\
\text { 4-layers transformer }(\mathrm{r}=38.5 \mu \mathrm{m})\end{array}$ & 1.9 & $21.69\left(C_{e q 3}\right)$ & $24.8 \mathrm{GHz}$ & $24 \mathrm{GHz}$ & 4.7 & $\begin{array}{c}5 \% \\
100 \times 100\end{array}$ \\
\hline Two-turns two-layers inductor $(\mathrm{r}=27 \mu \mathrm{m})$ & 2.2 & $67.2\left(C_{e q 4}\right)$ & $13.1 \mathrm{GHz}$ & $12.1 \mathrm{GHz}$ & $4.3 \%$ \\
\hline
\end{tabular}

TABLE V

3-D v.s. Planar BALUn PERformance Comparison

\begin{tabular}{|c|c|c|c|c|c|c|}
\hline Architecture & Insertion Loss (dB) & $\begin{array}{c}\text { Gain } \\
\text { Mismatch }(\mathrm{dB})\end{array}$ & $\begin{array}{c}\text { Phase } \\
\text { Mismatch (dB) }\end{array}$ & $\mathrm{f}_{\mathrm{SR}}(\mathrm{GHz})$ & $\mathrm{Q}(\max )$ & Area \\
\hline $\begin{array}{c}\text { 3-D } \\
\text { Balun }\end{array}$ & $<5 \mathrm{~dB} @ 6 \sim 10 \mathrm{GHz}$ & $\begin{array}{c}<0.6 \mathrm{~dB} \\
\text { (a) } 1 \sim 10 \mathrm{GHz}\end{array}$ & $\begin{array}{c}<7^{\circ} \\
\text { (a) } 1 \sim 10 \mathrm{GHz}\end{array}$ & 15.6 & 5.4 & $\begin{array}{c}100 \times 100 \\
28 \%\end{array}$ \\
\hline Planar Balun & $\begin{array}{c}<6.2 \mathrm{~dB} \\
\text { a. } 6 \sim 8 \mathrm{GHz}\end{array}$ & $\begin{array}{c}<0.8 \mathrm{~dB} \\
\text { a. } 5 \sim 8 \mathrm{GHz}\end{array}$ & $\begin{array}{c}<7^{\circ} \\
\text { (a) } 5 \sim 8 \mathrm{GHz}\end{array}$ & 10.4 & 6.8 & $\begin{array}{c}189 \times 189 \\
100 \%\end{array}$ \\
\hline
\end{tabular}

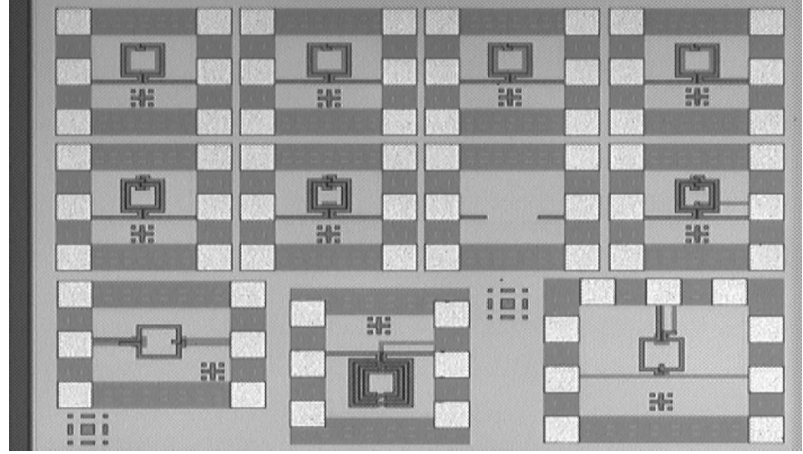

Fig. 20. Device micrograph.

[21]. All the devices are fabricated in a $0.18-\mu \mathrm{m} 1 \mathrm{P} 6 \mathrm{M}$ generic CMOS process. Fig. 20 shows the die photo. The de-embedded open kit is also built in for calibration [9]. Compared to conventional symmetrical planar counterparts, the proposed 3-D architectures manifest better self-resonant frequency and coupling coefficient while their chip areas are greatly reduced. The self-resonant frequency $\left(f_{\mathrm{SR}}\right)$ of the proposed 1 turn per layer architecture is improved by $32 \%$ to $61 \%$, while the chip area is reduced by $32 \%$ to $70 \%$. Quality factor improvements utilizing IMLS in the 3-D architectures are also proposed and discussed. The coupling coefficient $(K)$ of the transformer can be further improved by enhancing magnetic coupling and introducing electric coupling in a multi-turn multi-layer architecture, but the self-resonant frequency will be suffered. The measured $K$ is up to 0.77 at $8 \mathrm{GHz}$ in a two turns two layer architecture. The 1:1 transformer shows less than $0.1 \%$ inductance mismatch in a $18-\mathrm{GHz}$ range, and $K$ is up to 0.7 at $8 \mathrm{GHz}$. In addition, 3-D baluns can be easily derived by interleaving a 3-D inductor with a 3-D transformer. Both the baluns and transformer show wide band gain and phase matching. And finally, DCMs of the
3-D passive components are utilized in calculating their effective parasitic capacitance and analyzing the self-resonant frequency. They provide a convenient way and design insights in the performance evaluation.

\section{ACKNOWLEDGMENT}

The authors wish to thank CIC for chip fabrication, and acknowledge the assistance of Dr. K-W Huang for measurement support.

\section{REFERENCES}

[1] D. J. Cassan and J. R. Long, "A 1.V 0.9.dB NF low noise amplifier for 5-6-GHz WLAN in 0.18- $\mu \mathrm{m}$ CMOS," in Proc. IEEE Custom Integr. Circuits Conf., 2002, pp. 419-422.

[2] C. Hermann, M. Tiebout, and H. Klar, "A 0.6-V 1.6-mW transformer-based 2.5-GHz downconversion mixer with +5.4-dB gain and -2.8-dBm IIP3 in 0.13-um CMOS," IEEE Trans. Microw. Theory Tech., vol. 53, no. 2, pp. 488-495, Feb. 2005.

[3] P. Andreani, A. Bonfanti, L. Romano, and C. Samori, "Analysis and design of a 1.8-GHz CMOS LC quadrature VCO," IEEE J. Solid-State Circuits, vol. 37, no. 12, pp. 1737-1747, Dec. 2002.

[4] W.-Z. Chen, Y.-L. Cheng, and D.-S. Lin, "A 1.8 V, 10 Gbps fully integrated CMOS optical receiver analog front end," in Proc. Eur. SolidState Circuits Conf. (ESSCIRC'04), 2004, pp. 263-266.

[5] A. Zolfaghari, A. Chan, and B. Razavi, "Stacked inductors and transformers in CMOS technology," IEEE J. Solid-State Circuits, vol. 36, no. 4, pp. 620-628, Apr. 2001.

[6] C.-C. Tang, C.-H. Wu, and S.-I. Liu, "Miniature 3-D inductors in standard CMOS process," IEEE J. Solid-State Circuits, vol. 37, no. 4, pp. 471-480, Apr. 2002.

[7] M. Danesh and J. R. Long, "Differentially driven symmetric microstrip inductors," IEEE Trans. Microw. Theory Tech., vol. 50, no. 1, pp. 332-341, Jan. 2002.

[8] J. R. Long, "Monolithic transformers for silicon RF IC design," IEEE J. Solid-State Circuits, vol. 35, no. 9, pp. 1368-1382, Sep. 2000.

[9] C. P. Yue and S. S. Wong, "On-chip spiral inductors with patterned ground shields for Si-based RF IC's," IEEE J. Solid-State Circuits, vol. 33, no. 5, pp. 743-752, May 1998.

[10] M. Danesh, J. R. Long, R. A. Hadaway, and D. L. Harame, "A $Q$-factor enhancement technique for MMIC inductors," in Proc. IEEE RFIC Symp., 1998, pp. 217-220. 
[11] T. Liang, J. Gillis, D. Wang, and P. Cooper, "Design and modeling of compact on-chip transformer/Balun using multi-level metal winding for RF integrated circuit," in Proc. IEEE RFIC Symp., 2001, pp. $117-120$.

[12] J. N. Burghartz, M. Soyuer, and K. A. Jenkins, "Microwave inductors and capacitors in standard multilevel interconnect silicon technology," Proc. IEEE Trans. Microw. Theory Tech, vol. 44, no. 1, pp. 100-104, Jan. 1996.

[13] J. M. Lopez-Villegas, J. Cabanillas, J. A. Osorio, and J. Samitier, "Improvement of the quality factor of RF integrated inductors by layout optimization," IEEE Trans. Microw. Theory Tech, vol. 48, no. 1, pp. 76-83, Jan. 2000.

[14] A. Niknejad and R. G. Meyer, "Analysis, design, and optimization of spiral inductors and transformers for Si RF ICs," IEEE J. Solid-State Circuits, vol. 33, no. 10, pp. 1470-1481, Oct. 1998.

[15] J. R. Long and M. A. Copeland, "The modeling, characterization, and design of monolithic inductors for silicon RF IC' s," IEEE J. Solid-State Circuits, vol. 32, no. 3, pp. 357-369, Mar. 1997.

[16] S. S. Mohan, M. M. Hershenson, S. P. Boyd, and T. H. Lee, "Simple accurate expressions for planar spiral inductances," IEEE J. Solid-State Circuits, vol. 34, no. 10, pp. 1419-1424, Oct. 1999.

[17] S. Jenei, B. K. J. C. Nauwelaers, and S. Decoutere, "Physics-based closed-form inductance expression for compact modeling of integrated spiral inductors," IEEE J. Solid-State Circuits, vol. 37, no. 1, pp. 77-80, Jan. 2002.

[18] C. P. Yue, C. Ryu, J. Lau, T. H. Lee, and S. S. Wong, "A physical model for planar spiral inductor on silicon," in Dig. Tech. Papers IEEE IEDM, 1996, pp. 155-158.

[19] K. Y. Tong and C. Tsui, "A physical analytical model of multilayer on-chip inductors," IEEE Trans. Microw. Theory Tech, vol. 53, no. 4, pp. 1143-1148, Apr. 2005.

[20] W. B. Kuhn and N. M. Ibrahim, "Analysis of current crowding effects in multiturn spiral inductors," IEEE Trans. Microw. Theory Tech, vol. 49, no. 1, pp. 31-38, Jan. 2001.

[21] W.-Z. Chen and W.-H. Chen, "Symmetric 3-D passive components for RF ICs application," in Dig. Tech. Paper IEEE RFIC Symp. s, Jun. 2003, pp. 599-602.

[22] C.-H. Wu, C.-C. Tang, and S.-I. Liu, "Analysis of on-chip spiral inductors using the distributed capacitance model," IEEE J. Solid-State Circuits, vol. 38, no. 6, pp. 1040-1044, Jun. 2003.

[23] TSMC $0.18-\mu \mathrm{m}$ mixed-signal salicide (1P6M, $1.8 \mathrm{~V} / 3.3 \mathrm{~V}$ ) SPICE models Taiwan Semiconductor Manufacturing Co, Hsin-Chu, Taiwan, R.O.C., 2004.

[24] W.-Z. Chen and K.-C. Hsu, "Miniaturized 3-dimensional transformer design," in Proc. 2005 IEEE Custom Integr. Circuits Conf., pp. 285-288.

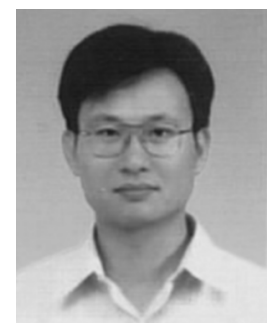

Wei-Zen Chen (M'99) received the B.S., M.S., and $\mathrm{Ph} . \mathrm{D}$. degree in electronics engineering from National Chiao-Tung University, Hsin-Chu, Taiwan, R.O.C., in 1992, 1994, and 1999, respectively.

He worked for Industrial Technology Research Institute (ITRI), Hsin-Chu, Tawian R.O.C., on RF integrated circuit design in 1999. From 1999-2002, he was with the department of Electrical Engineering, National Central University, Chung-Li, Tawian, R.O.C. Since 2002, he has been with the Department of Electronics Engineering, National Chiao-Tung University, where he is currently an Associate Professor. His research interests are integrated circuits and systems for high speed networks and wireless communications.

Dr. Chen is a member of Phi Tau Phi.

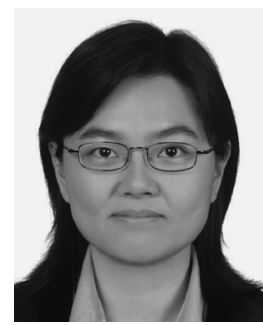

Wen-Hui Chen was born in Hsin-Chu, Taiwan, R.O.C., in 1979. She received the B.S. and M.S. degree in electrical engineering from National Central University, Chung-Li, Taiwan, R.O.C., in 2001 and 2003, respectively.

From 2003 to 2005, she was an Engineer in the R\&D Division of VIA Optical Solution, Inc. Currently, she works for Industrial Technology Research Institute (ITRI) SoC Technology Center, Hsin-Chu, Taiwan, R.O.C., on mixed-signal circuit design. Her research interest is CMOS mixed-signal

circuit design.

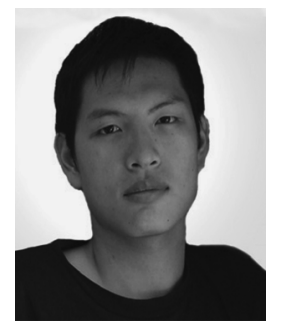

Kuo-Ching Hsu was born in Taipei, Taiwan, R.O.C., in 1982. He received the B.S. degree in communication engineering in 2004, from National Chiao-Tung University, Hsin-Chu, Taiwan, R.O.C., where he is currently working toward the M.S. degree in electonics engineering.

His research interests include high-frequency passive components design, phase locked-loop, and high-speed clock and data recovery circuit design for multiple gigabit communication. 